Review

\title{
Bordetella Adenylate Cyclase-Hemolysin Toxins
}

\author{
Nicole Guiso \\ Institut Pasteur Unité de Prévention et Thérapies Moléculaires des Maladies Humaines, 25 rue du Dr. Roux, \\ 75015 Paris, France; nicole.guiso@pasteur.fr; Tel.: +00-33-685-827-328 \\ Academic Editor: Joachim Orth \\ Received: 22 August 2017; Accepted: 7 September 2017; Published: 11 September 2017
}

\begin{abstract}
Adenylate cyclase-hemolysin toxin is secreted and produced by three classical species of the genus Bordetella: Bordetella pertussis, B. parapertussis and B. bronchiseptica. This toxin has several properties such as: (i) adenylate cyclase activity, enhanced after interaction with the eukaryotic protein, calmodulin; (ii) a pore-forming activity; (iii) an invasive activity. It plays an important role in the pathogenesis of these Bordetella species responsible for whooping cough in humans or persistent respiratory infections in mammals, by modulating host immune responses. In contrast with other Bordetella toxins or adhesins, lack of (or very low polymorphism) is observed in the structural gene encoding this toxin, supporting its importance as well as a potential role as a vaccine antigen against whooping cough. In this article, an overview of the investigations undertaken on this toxin is presented.
\end{abstract}

Keywords: Bordetella species; adenylate cyclase toxin; vaccine antigen

\section{Introduction}

The genus Bordetella comprises nine species. Among them, B. pertussis, B. parapertussis and B. bronchiseptica are so closely related, despite differences in host range, that they are often considered as subspecies of the same species and are called "classical species" [1]. B. pertussis is the agent of whooping cough, a severe respiratory disease in humans which can be dramatic for newborns and elderly subjects. B. parapertussis is the agent of respiratory disease in sheep and in humans; however, the clinical symptoms induced in humans last less than those induced by $B$. pertussis although clinically similar $[2,3]$. B. bronchiseptica is a respiratory pathogen for several mammal species and sometimes for immuno-suppressed patients [1]. B. pertussis and B. parapertussis appear to have independently emerged from a $B$. bronchiseptica ancestor through rearrangement and loss of genetic material $[4,5]$. Those three species are closely related and produce similar as well as specific virulence factors. The three species produce (i) similar adhesins such as filamentous hemagglutinin (FHA) and pertactin (PRN), but different fimbrial proteins (FIM); (ii) similar toxins such as adenylate cyclase-hemolysin (AC-Hly) toxin, tracheal cytotoxin and dermonecrotic toxin, but B. pertussis is the only species producing pertussis toxin (PT); (iii) B. bronchiseptica is the only species producing a flagellum, a functional Bordetella type-III secretion system effector A, and a type-VI secretion system [6-8]. In this review we will only focus on the properties of the AC-Hly toxin common to the three species.

\section{Bordetella pertussis Adenylate Cyclase-Hemolysin Toxin}

\subsection{Structure}

B. pertussis AC-Hly (Bp AC-Hly) was discovered in 1976 [9] and soon after shown to invade phagocytic cells and inhibit phagocytosis and oxidative burst in human neutrophils [10]. 
Since the sequencing of its structural gene, cyaA [11], it has been known that Bp AC-Hly toxin belongs to the Repeats in ToXins (RTX) family composed of toxins secreted by Gram-negative bacteria. These RTX toxins share several features such as (i) post-translational modification; (ii) C-terminal unprocessed secretion signal; (iii) export out of the cell by type I secretion systems (T1SS); and (iv) a C-terminal calcium-binding domain consisting of acidic glycine-rich nonapeptide repeats. Furthermore, most RTX toxins penetrate and permeabilize host cells. [12].

Bp AC-Hly is a 1706 amino acid protein containing several domains (i) an N-terminal adenylate cyclase domain of 364 amino acid residues; (ii) a translocation domain between residues 365 to 500; (iii) an hydrophobic domain between residues 500 to 750; (iv) a domain containing the two post-translational sites (Lys 860 and Lys 983) between residues 750 to 1000; and (v) a typical calcium-binding domain containing repeats of glycine and aspartate nona-peptides binding calcium, similar to all RTX toxins, between residues 1000 and 1706. This domain contains the receptor binding site and the C-terminal secretion system $[13,14]$.

The post-translational modifications of Bp AC-Hly, first demonstrated by Barry et al. [15], are performed by an acyl-translational enzyme encoded by the cyaC gene. Acylation is essential for tight binding and interaction with human cells as well as for toxin activities [13]. Hackett et al. [16] showed that Bp AC-Hly is post-translationally modified by a palmitoylation on Lys 983 . However, later it was found that the recombinant Bp AC-Hly toxin produced in Escherichia coli K-12, in presence of the cyaC protein, was also modified on Lys 860 [17]. Recently, we compared the post-translational modifications (PTM) of the Bp AC-Hly produced by the reference strain B. pertussis Tohama and by different recent B. pertussis clinical isolates. We showed that Bp AC-Hly harbors PTM at both sites: palmitoylations on Lysine 860 and palmoylations and myristoylations on Lysine 983 [18].

Three proteins, encoded by the cyaBDE genes of a Type I secretion system, are implicated in the secretion of the toxin. The secretion occurs directly from bacterial cytosol into the extracellular medium [12].

Bp AC-Hly interacts with two other virulence factors produced by B. pertussis, FHA [19] and PRN [20]. A direct physical interaction was characterized between AC-Hly toxin and FHA. This interaction may help to increase the local concentration of the toxin on the B. pertussis outer membrane. Adherence to host cells, mediated by FHA, may be coupled to AC-Hly toxin delivery [19]. These interactions might be of high importance for the conformation and maximal activity of the toxin.

\subsection{Regulation of Expression}

The expression of this toxin is regulated by the two-component system called the BvgAS system [6], which also controls the expression of several other virulence factors of B. pertussis. The BvgAS system responds to environmental signals such as temperature, or biochemical signals such as nicotinic acid or sulfate, and allows the expression of the virulence factors. Experiments with mutants, deficient of BvgAS expression, demonstrated that this expression is necessary and sufficient for respiratory infection using a murine respiratory model [6].

However, expression of Bp AC-Hly was shown to be also regulated by other factors such as the anti-sigma factor RseA [21]. Recently, it was demonstrated that Rpo-E, a sigma factor which responds to environmental stresses, can indirectly modulate Bp AC-Hly, as well as PT, expression, through mechanisms under investigation [22]. It can be hypothesized that this is the basis of the increase in expression of AC-Hly by B. pertussis observed after collection of bacteria from the lungs of infected mice [23,24].

B. pertussis isolates, collected from human nasopharyngeal samples, can also produce more AC-Hly because they harbor a duplication of the cya locus [25]. These isolates are found to be not more virulent in the murine respiratory model or in a cellular model. However, this failure to demonstrate any difference could be due to the high instability of these isolates. It is possible that AC-Hly overexpression is necessary during human infection but not in vitro, or that it is unstable in vitro. Furthermore, the murine model may not be the best model for comparing clones producing 
different levels of AC-Hly. In fact, AC-Hly might have a higher affinity for the human receptor than for the murine receptor. It has also been shown that efficient secretion of AC-Hly requires an interaction with FHA [19]. As the isolate harboring a duplication of the cyaA gene produces more AC-Hly but not more FHA, it is possible that the excess of AC-Hly is not able to interact efficiently with host cells. Further studies are required to determine whether duplication of $c y a A$ gene as well as an increase in production of AC-Hly in vivo, play a role during human infection.

Clinical isolates, not producing FHA, show also different transcriptomic behaviour since the expression of $p t x \mathrm{~A}, c y a A$ or prn genes is significantly increased as compared to clinical isolates producing FHA. We are wondering whether this could be a consequence of different regulation, since in these isolates no sequence difference in the bvg operon was found [26]. Precise clinical and molecular analyses of isolates freshly collected from infected humans are, therefore, especially important.

\subsection{Biological Activities}

Bp AC-Hly possesses a cell-invasive adenylate cyclase activity and a haemolysin activity. After secretion in the extracellular milieu, Bp AC-Hly binds calcium, and folds into a stable $\beta$-sheet conformation that is required for efficient binding to target host cells [27]. The receptor of Bp AC-Hly on host cells is the complement receptor 3 (CR3 or CD11b/CD18 integrin) [28]. Post-translational acylation enhances binding of Bp AC-Hly to CR3 on the surface of phagocytes [29]. However, with lower efficacy $\mathrm{Bp}$, AC-Hly can also penetrate cells lacking the CR3 receptor [30]. After binding to the host cell, Bp AC-Hly is able to translocate the AC domain. Karst et al., showed that deletion of residues 375 to 485 within Bp AC-Hly totally abrogated the toxin's ability to increase intracellular cAMP in target cells [31]. These results indicate that, while the calmodulin-dependent adenylate cyclase activity is located between the amino acid residues 1 to 384, the membrane-interacting, translocation-competent domain extends up to residue 489 [31].

Furthermore, Bp AC-Hly is also, after oligomerization, a pore-forming cell, responsible for the haemolysis of sheep or horse erythrocytes but not human erythrocytes when incubated using the Bordet Gengou medium [13]. Both invasive and pore-forming activities depend on the post-translational modifications of AC-Hly [13]. Gray et al., demonstrated that close association of live B. pertussis bacteria with host cells and ongoing active synthesis and secretion of Bp AC-Hly, are required for delivery of the toxin into target cells. The bacterial surface-associated toxin was found to be unable to penetrate host cells [32].

\subsection{Role As a Toxin}

The first experiment demonstrating that Bp AC-Hly acts as a toxin was reported by Weiss et al. who showed that Tn5-induced B. pertussis mutants, non-producing this enzyme, were non-lethal in a murine model [33]. Both adenylate cyclase and hemolytic activities are required for B. pertussis to initiate infection [34]. However, using different $B$. pertussis mutants, it has been recently demonstrated that neither the pore-forming (hemolytic) activity of Bp AC-Hly toxin on CD11b phagocytes nor its capacity to elevate cAMP in CD11b cells is per se required for persistent sub-lethal infection of mouse lungs by B. pertussis. These capacities, however, are involved in B. pertussis penetration across the epithelial lining, provoking enhanced neutrophil infiltration and inflammatory damage of infected tissue [35].

The characterized roles of Bp AC-Hly as a toxin are the following:

(i) Bp AC-Hly is able to induce apoptosis of macrophages in vitro and in vivo [36,37]. Apoptotic death of bronchopulmonary cells in vivo was observed exclusively following intranasal infection with bacteria re-isolated from the lungs of infected mice and not with B. pertussis collected after in vitro subculture [24]. Depletion of ATP, as a result of adenylate cyclase activity, might be sufficient for macrophage cytotoxicity, but an unconventional calcium influx mediated by the translocating AC domain may also contribute to cytotoxic effects [38,39]. Bp AC-Hly-deficient mutants were shown to be more efficiently phagocytosed by human neutrophils [40], stressing the importance of Bp 
AC-Hly in targeting phagocytic cells for B. pertussis pathogenesis. However, neutrophil depletion did not enhance infection by Bp AC-Hly-deficient B. pertussis mutants in naive mice, but in neutrophil-depleted immune (previously infected) mice; the Bp AC-Hly-deficient mutants are as virulent as the parental strain, indicating that the toxin is important in neutrophil inhibition only in the presence of opsonizing antibodies [41].

(ii) B. pertussis, as well as Bp AC-Hly, are not cytotoxic for human tracheal epithelial cells [42]. However, we observed induction of IL-6 production by Bp AC-Hly in human tracheal epithelial cells in vitro [43], which enhances recruitment of neutrophils during infection. This observation correlates with our in vivo experiments using the murine respiratory model [24,44].

(iii) Bp AC-Hly production, as well as that of PRN (probably indirectly via its interaction with AC-Hly), inhibits invasion of B. pertussis in human tracheal cells, whereas FHA favors this process [42]. It is possible that $B$. pertussis could have evolved anti-invasive mechanisms such as production of AC-Hly to avoid destruction within tracheal epithelial cells. Martin et al., using B. pertussis recombinant AC-Hly, showed that the toxin promotes bacterial internalization into non-phagocytic cells. They hypothesize that this internalization favors the persistence of the bacteria in the host. However, they didn't (a) use human tracheal cells, (b) verify the survival of the bacteria inside the cells, and (c) discuss the fact that B. pertussis was not shown to induce persistent or chronic infection in humans, even in immuno-suppressed patients in contrast to some other Bordetella species [45]. Further experiments are, therefore, required to investigate these issues.

(iv) While the action of Bp AC-Hly appears to first inhibit bactericidal functions of host innate immunity, such as neutrophils and macrophages, the toxin is likely to have effects on adaptive immunity as well. Bp AC-Hly might mediate an escape strategy for the bacterium, since it reduces Th1 immunity and increases Th17 responses thought to be responsible for enhanced lung inflammation [24,37,44,46-49].

All the data presented demonstrate that Bp AC-Hly plays an important role during the disease induced by B. pertussis. Most of these data derived from in vitro as well as in vivo studies (mostly using the murine respiratory model) and the relevance of these activities to B. pertussis infection in humans and pathogenesis remains to be determined. However, a high amount of AC-Hly has recently been detected in nasopharyngeal washes from diseased infants [50], supporting the case for a role of this toxin in respiratory functions in humans.

\subsection{Immunogenicity}

Bp AC-Hly is highly immunogenic. Antibodies are detected in serum of infected non-vaccinated subjects [51-54]. Since none of the actual pertussis acellular vaccines contain Bp AC-Hly, it was proposed to use Bp AC-Hly as an antigen for diagnosis. However, because of its similarities with AC-Hly produced by B. parapertussis and B. bronchiseptica (as well as other RTX toxins), the results were non-specific. PT antigen remains the only antigen to be used since it is the only one specific to B. pertussis $[53,55]$. Detection of anti-Bp AC-Hly antibodies is variable after vaccination with pertussis whole-cell vaccines $[51,53]$. However, detection of the antibody following vaccination may vary according to the pertussis whole-cell vaccine used.

Also a lack or low levels of anti-AC-Hly antibodies has been detected in the serums of children who did not respond to pertussis whole-cell or pertussis acellular vaccines. This could be linked to the "antigenic sin" phenomenon. More studies in vaccinated and infected subjects (children, but also adults) are necessary in order to analyze these findings obtained on low numbers of children.

Recently, Eby et al. [54] demonstrated that anti AC-Hly antibodies developed by humans following infection with $B$. pertussis consistently neutralize toxin-induced cytotoxicity. They suggest that toxin-neutralization assay can be used to characterize the immunological response to AC-Hly after infection and vaccination [54]. 


\subsection{Role as a Protective Antigen}

At the end of the 1980s, we showed, using the murine respiratory model, that purified Bp AC-Hly can induce a protective immunity against B. pertussis infection [56].

Using recombinant Bp AC-Hly (r-Bp AC-Hly), produced by E. coli K-12, it has been demonstrated for the first time that $\mathrm{r}-\mathrm{Bp} \mathrm{AC}-\mathrm{Hly}$ is a protective antigen in mice [52]. We showed that the cyaC-mediated modifications of the protein are important to induce a protective activity. The region bearing the modifications may be part of an immuno-dominant epitope or the cyaC-mediated modifications may affect the conformation of the molecule, exposing immuno-dominant epitopes [57]. Surprisingly, we also observed that the protective and hemolytic activities of r-Bp AC-Hly were lower than those of Bp AC-Hly produced by B. pertussis, while its invasive activity was higher, suggesting that the PTM of AC-Hly in B. pertussis and that in E. coli K-12 may differ. These observations correlated with the previous data of Hackett et al. [17]. However, in light of our recent data concerning the PTM of Bp AC-Hly produced by B. pertussis [18], we favor the hypothesis that the conformation of both proteins might be different because of the lack of interaction of the r-BpAC-Hly with FHA.

We further used a set of purified fragments of the r-AC-Hly to localize the protective epitopes on the protein. We showed that the structure of the modification-and-repeat region of r-Bp AC-Hly is critical for its protective activity. Furthermore, specific anti-AC-Hly antibodies present in the serum of B. pertussis-infected mice and humans are directed, predominantly, against the last 800 amino acids [52]. These antibodies appeared to recognize conformational epitopes present only in a structure formed by the intact C-terminal half of the toxin. However, we didn't observe any correlation between the capacity of the fragments to induce both toxin-neutralizing antibodies upon immunization of mice and protective immunity, suggesting that the presence of antibodies neutralizing AC-Hly toxin activity might not be a reliable measure of the induced protection against infection by B. pertussis [52].

Recently, Wang and Maynard [58,59] confirmed that the C-terminal domain of the toxin is immuno-dominant and elicits neutralizing antibodies, occluding the receptor-binding site. Using several B. pertussis isolates, we didn't find any polymorphism on this C-terminal domain, carrying protective epitopes and the receptor-binding site for human cells of AC-Hly. This finding is also in favor of the important role of AC-Hly in B. pertussis pathogenesis [60].

However, another region of the toxin, located between amino acid 380-400 and implicated in the translocation of the adenylate cyclase domain [14] is also important. In fact, a monoclonal antibody, able to protect against B. pertussis infection, recognizes an epitope localized in this region [61]. Specific polyclonal anti-Bp-AC-Hly antibodies were also shown to be protective against B. pertussis infection [62].

Using the murine respiratory model, another property of the Bp AC-Hly has been characterized. It has been observed that inactive Bp AC-Hly enhances protection induced by other pertussis antigens against $B$. pertussis infection, with adjuvant effects on both Th1 and Th2 immune responses [63,64].

\section{Bordetella parapertussis and B. bronchiseptica Adenylate Cyclase-Hemolysin Toxins}

The three classical Bordetella species are often considered as subspecies of one species $[1,65]$. However, it must be noted that the B. bronchiseptica species is much more diverse than the B. pertussis and B. parapertussis species [1]. Furthermore, despite their similarities, their interactions with the human host are not the same. B. pertussis and B. parapertussis $s_{h u}$ are the agents of whooping cough. However, while B. pertussis produces specifically PT, two fimbrial proteins FIM2 and FIM3, and its lipopolysaccharide (LPS) does not possess an $\mathrm{O}$ antigen, B. parapertussis does not produce PT, FIM2 and FIM3, and its LPS possesses an O antigen. B. bronchiseptica does not produce PT either, but produces and secretes the Bordetella type-III secretion system effector A (BteA), a type-VI secretion system, and possesses an LPS presenting high intra-species structural variations $[6,8,66]$. These discrepancies in the production of virulence factors may explain the difference in these species' host range, in their behavior inside their host, as well as transmission and adaptability to their environment [1]. However, the three species produce AC-Hly. 


\subsection{Structure}

The structure of the cya locus on the chromosome of B. parapertussis (Bpp AC-Hly) and B. bronchiseptica (Bbs AC-Hly) is similar to that of B. pertussis according to the gene sequence $[5,67]$. The three proteins possess similar adenylate cyclase and haemolytic activities [34,68]. However, few studies were performed on purified Bpp and Bbs AC-Hly. Recently, we determined the PTM of Bpp AC-Hly produced by the reference strain B. parapertussis 12,822 and different recent $B$. parapertussis clinical isolates [18]. All Bpp-AC-Hly harbor two PTM corresponding mostly to palmytoylations on Lysine 994 and myristoylations on Lysine 1017 [18].

\subsection{Regulation of Expression}

The expression of Bpp and Bbs AC-Hly are also under the control of the two-component system BvgAS. As observed for Bp AC-Hly, there is probably another regulation in vivo since an increase of expression of Bpp AC-Hly and Bbs AC-Hly by isolates, freshly isolated from lungs of infected mice, is observed $[23,24]$.

\subsection{Biological Activities}

In similarity with Bp AC-Hly, the C-terminal part of the Bpp AC-Hly, located between nucleotide 2569 and nucleotide 5121, i.e., from AA857 to AA1706, is conserved. However, in contrast to Bp AC-Hly, Bpp AC-Hly is not cytotoxic for macrophages [18]. This difference might be due either to the different PTM harboured by the two toxins or to different interactions with FHA, PRN or LPS. It is well known that Bpp LPS contains an O antigen, contrary to Bp LPS [69], and it was previously shown that interactions between LPS and RTX toxins are important $[70,71]$.

In contrast to Bp AC-Hly and Bpp AC-Hly, variability is observed with the Bbs C-terminal cyaA gene, i.e., between nucleotide 2569 and nucleotide 5121. We identified 14 alleles among 87 isolates analysed [60] and this list might not be exhaustive. Fourteen of the amino acid changes are located on the $\mathrm{CD} 11 \mathrm{~b} / \mathrm{CD} 18$ binding site and might be linked to the sequence differences of the integrin receptor of the various hosts of $B$. bronchiseptica species. However, the $14 \mathrm{Bbs} c y a A$ alleles are not host-specific, since they are identified in isolates of either human or animal origin.

As previously shown [60,72], several B. bronchiseptica isolates do not express the toxin, due to a frameshift or a non-sense mutation in the cyaA gene or a deletion of the entire cyaA gene. In the case of the deletion of the gene, we observed, as per Buboltz et al. [73], that the cya operon is replaced by the $p t p$ operon.

Absence of production of an AC-Hly product was observed only in B. bronchiseptica isolates independent of their human or animal origin, and this might be at the origin of some peculiarity of the disease induced by this species. We previously showed that expression of the toxin inhibits the invasive properties of B. pertussis in epithelial cells [42], and all B. pertussis isolates presently express it. As a corollary, no chronic infection has been described to date in humans, even in immuno-compromised subjects, following infection with B. pertussis. In contrast, it is known that $B$. bronchiseptica is able to induce chronic infection in mammals $[1,72,74]$, mainly in elderly or immune-compromised patients. Therefore, it is likely that persistence of the infection is favored by the absence of expression of AC-Hly, although the role of this toxin could also be compensated for by expression of another factor, as suggested by Buboltz et al. [73]. It is possible to hypothesize that its expression would be detrimental at some stages of the infectious cycle of B. bronchiseptica during chronic infection, although necessary for initiating the infection.

Using the murine model of respiratory infection, it has been shown that both humoral- and cellular-mediated immunities play an important role in the elimination of B. bronchiseptica infection [75]. Furthermore, we observed that, after B. bronchiseptica infection, a rapid T-cell response is generated to Bbs AC-Hly which is accompanied by an early synthesis of specific AC-Hly antibodies. The importance 
of Bbs AC-Hly was also confirmed using a porcine model [76]. These results support our previous data showing that Bordetella AC-Hly plays an important role in Bordetella pathogenesis.

In the last few years, B. pertussis and B. bronchiseptica have been shown to be able to form biofilms that may play a role in the pathogenesis of these organisms $[77,78]$. It was observed that a B. bronchiseptica mutant lacking AC-Hly produced more biofilm than the parental strain. Furthermore, exogenous AC-Hly inhibits biofilm formation and the $\mathrm{N}$-terminal catalytic domain (AC domain) of the toxin is necessary and sufficient for this inhibitory effect. The AC domain might interact with the C-terminal segment of FHA [78].

\subsection{Role As a Protective Antigen}

In similarity with Bp AC-Hly, Bpp AC-Hly and Bbs AC-Hly induce a protective immunity against $B$. parapertussis and B. bronchiseptica infections, respectively $[68,79]$. Since B. parapertussis and B. bronchiseptica express virulence factors, such as FHA, PRN or AC-Hly, that possess a very strong degree of homology with $B$. pertussis virulence factors, one could expect that an acellular preparation containing these $B$. pertussis antigens would protect against $B$. parapertussis and B. bronchiseptica infections. Using purified virulence factors, we demonstrated that it is not the case $[68,79]$, suggesting that the ability of protective antigens to stimulate an effective immune response is species specific.

The different PTM harbored by Bp AC-Hly and Bpp AC-Hly might be at the origin of the specificity of protection [18]. The other hypothesis might be a different conformation following interactions with other bacterial factors produced by B. pertussis and B. parapertussis, such as FHA, PRN or LPS, known to be different between the two species $[5,69,80,81]$.

\section{Conclusions}

By contrast with other Bordetella adhesins or toxins, AC-Hly is one of the few virulence factors that is produced by the three classical pathogenic Bordetella species. All the data presented in this review demonstrate that AC-Hly plays a critical role during the disease induced by the classical Bordetella species. Furthermore, to the best of our knowledge, no, or very low, polymorphism of the AC-Hly toxin produced by the two human species is observed [18].

The adjuvant and immunomodulatory properties of the inactive Bp AC-Hly also suggest that it has potential as a vaccine component through enhancement of Th1-oriented cell-mediated immune responses.

For all these reasons, many experts in the field propose to include Bp AC-Hly in pertussis acellular vaccines. However, there are still several issues that need to be solved:

(i) Can genetically inactivated BP AC-Hly produced by B. pertussis be used? A B. pertussis mutant carrying double mutations in the $c y a A$ gene could be used [82]. This double mutant produces a toxoid devoid of both adenylate cyclase and pore-forming activities that may be a suitable antigen for inclusion in a next generation of acellular pertussis vaccines [82]. However, it is well known that the amount of AC-Hly produced by B. pertussis is very low. Moreover, Bp AC-Hly is a hydrophobic protein that aggregates or is degraded during purification and needs urea to be solubilized [14,83];

(ii) Can the genetically detoxified $r-B p A C-H l y$, produced by E. coli K-12, be used? It has been demonstrated that large-scale production of detoxified r-Bp AC-Hly is now possible and clinical cGMP batches have been produced and tested as safe in Phase I clinical trials of T-cell vaccines developed for cancer immunotherapy [83]. However, it was previously shown that the protective activity of Bp AC-Hly and r-Bp AC-Hly were different. This was hypothesized to be due to the different PTM of both proteins [17]. However, we recently showed that this might not be the case [18]. We favor the hypothesis that the difference might be due to the interactions with FHA, PRN and LPS for the final conformation of Bp AC-Hly $[19,20,70,71]$. Additional investigations are, therefore, requested to test the detoxified $\mathrm{r}-\mathrm{Bp} \mathrm{AC}-\mathrm{Hly}$ as an antigen; 
(iii) Can the recombinant monomeric polypeptide which has been recently isolated [14] be used? First, it is necessary to demonstrate that a detoxified monomer induces a protective immunity. Moreover, the production of a high amount of monomeric polypeptide remains to be solved;

(iv) Can the C-terminal fragment of the toxin produced by E. coli K-12 (and bearing the PTM) be used? It needs to be confirmed that this recombinant fragment, which induces the synthesis of neutralizing antibodies, also induces a protective immunity, at least in the murine model $[58,59]$. In fact, we showed, using several different fragments of the r-Bp AC-Hly, that there is no correlation between induction of the neutralizing antibody and induction of a protective immunity [52];

(v) Can Outer Membrane Vesicule (OMV) produced by B. pertussis be used? Bacterial OMV naturally contain bacterial surface antigens. The composition of the pertussis OMV was characterized as containing $>200$ protein components, including the virulence factors PT, PRN, FHA, FIM and AC-Hly. [84,85]. The production of Bp OMV has been developed: (a) the interactions between virulence factors and LPS are preserved; (b) they are immunogenic; (c) they induce an immunity close to that induced after natural infection; (d) they are less reactogenic than pertussis whole-cell vaccines; and (e) induce a protective immunity [84,85]. Furthermore, they contain more antigens than pertussis acellular vaccines and so are less susceptible to inducing the phenomenon of "antigenic sin" [53]. Detoxified Bp OMV can be developed. However, this development will also need further research;

(vi) Can a mixture of B. pertussis and B. parapertussis OMVs be used? As shown in France, the circulation of $B$. parapertussis has been slowly increasing for a decade [86]. The increase can be due either to the use of pertussis acellular vaccine or to the evolution of the Bordetella species [1,87]. The circulation of B. parapertussis has also now been detected in the USA, a country using an acellular pertussis vaccine, but also in Pakistan, a country using a whole-cell pertussis vaccine $[3,88]$. This means that it could be advantageous to use a vaccine containing both detoxified Bp OMV and Bpp OMV, although it has been shown that Bpp OMV might induce protection against B. pertussis and B. parapertussis infection [84].

In conclusion, the different properties of the AC-Hly produced by the classical Bordetella species described above indicate clearly that this protein plays an important role during the infection induced by these bacteria. Furthermore, no, or very low, polymorphism of the cyaA gene in B. pertussis and B. parapertussis isolates was observed, underlining the importance of AC-Hly in the virulence of these two species, which are pathogenic for humans. The absence of AC-Hly expression by some $B$. bronchiseptica isolates might be related to the specific properties of $B$. bronchiseptica isolates, in particular, their capacity to induce chronic infections. AC-Hly expression might be essential for B. bronchiseptica, but not for its persistence inside the host. The polymorphism associated with diversifying selection in B. bronchiseptica species might be due to the fact that this species is able to induce chronic infections in a large number of mammalian species, during which it was previously shown that antigen expression varies [72,74].

The introduction of detoxified Bp AC-Hly or r-Bp AC-Hly in pertussis acellular vaccines is of great interest but still requires extensive and lengthy investigation. In particular, the role of interactions with other Bordetella vaccine antigens, such as FHA and PRN, in the final conformation of the toxin must be clarified. The use of detoxified Bp and Bpp OMV is of interest, since these interactions between the different Bordetella virulence factors are maintained.

Acknowledgments: This review is dedicated to Dr Simonetta Nicosia, a great scientist who passed away much too young, in 2002. She spent lots of time and energy working, among other domains, on eukaryotic adenylate cyclase.

Conflicts of Interest: The authors declare no conflict of interest. 


\section{References}

1. Guiso, N.; Hegerle, N. Other Bordetella's, lessons for and from pertussis vaccines. Expert Rev. Vaccines 2014. [CrossRef] [PubMed]

2. Novotny, P. Pathogenesis in Bordetella species. J. Infect. Dis. 1990, 161, 581-583. [CrossRef] [PubMed]

3. Karalius, V.P.; Rucinski, S.L.; Mandrekar, J.N.; Patel, R. Bordetella parapertussis outbreak in South Eastern Minnesota and the United States, 2014. Medicine 2017, 96, e6730. [CrossRef] [PubMed]

4. Diavatopoulos, D.A.; Cummings, C.A.; Schouls, L.M.; Brinig, M.M.; Relman, D.A.; Mooi, F.R. Bordetella pertussis, the causative agent of whooping cough, evolved from a distinct, human-associated lineage of B. bronchiseptica. PLoS Pathog. 2005, 1, e45. [CrossRef] [PubMed]

5. Parkhill, J.; Sebaihia, M.A.; Preston, L.D.; Murphy, N.; Thomson, D.E.; Harris, M.T.; Holden, C.M.; Churcher, S.D.; Bentley, K.L.; Mungall, A.M.; et al. Comparative analysis of the genome sequences of Bordetella pertussis, Bordetella parapertussis and Bordetella bronchiseptica. Nat. Genet. 2003, 35, 32-40. [CrossRef] [PubMed]

6. Melvin, J.A.; Scheller, E.V.; Miller, J.F.; Cotter, P.A. Bordetella pertussis pathogenesis: Current and future challenges. Nat. Rev. Microbiol. 2014, 12, 274-288. [CrossRef] [PubMed]

7. Hegerle, N.; Rayat, L.; Dore, G.; Zidane, N.; Bedouelle, H.; Guiso, N. In Vitro and in vivo analysis of the expression of the Bordetella type three secretion system effector A in Bordetella bronchiseptica, Bordetella pertussis and Bordetella parapertussis. Microbes Infect. 2013, 15, 399-408. [CrossRef] [PubMed]

8. Weyrich, L.S.; Rolin, O.Y.; Muse, S.J.; Park, J.; Spidale, N.; Kennett, M.J.; Hester, S.E.; Chen, C.; Dudley, E.G.; Harvill, E.T. A type VI secretion system encoding locus is required for $B$. bronchiseptica immunomodulation and persistence in vivo. PLoS ONE 2012, 7, e45892. [CrossRef] [PubMed]

9. Hewlett, E.L.; Urban, M.A.; Manclark, C.R.; Wolff, J. Extracytoplasmic adenylate cyclase of Bordetella pertussis. Proc. Natl. Acad. Sci. USA 1976, 73, 1926-1930. [CrossRef] [PubMed]

10. Confer, D.L.; Eaton, J.W. Phagocyte impotence caused by an invasive bacterial adenylate cyclase. Science 1982, 217, 948-950. [CrossRef] [PubMed]

11. Glaser, P.; Ladant, D.; Sezer, O.; Pichot, F.; Ullmann, A.; Danchin, A. The calmodulin-sensitive adenylate cyclase of Bordetella pertussis: Cloning and expression in Escherichia coli. Mol. Microbiol. 1988, 2, 19-30. [CrossRef] [PubMed]

12. Linhartova, I.; Bumba, L.; Masin, J.; Basler, M.; Osička, R.; Kamanová, J.; Procházková, K.; Adkins, I.; Hejnová-Holubová, J.; Sadílková, L.; et al. RTX proteins: A highly diverse family secreted by a common mechanism. FEMS Microbiol. Rev. 2010, 34, 1076-1112. [CrossRef] [PubMed]

13. Masin, J.; Osicka, R.; Bumba, L.; Sebo, P. Bordetella adenylate cyclase: A unique combination of pore-forming moiety with cell-invading adenylatecycmase enzyme. FEMS Pathog. Dis. 2015. [CrossRef] [PubMed]

14. Cannella, S.E.; Ntsogo Enguéné, V.Y.; Davi, M.; Malosse, C.; Sotomayor Pérez, A.C.; Chamot-Rooke, J.; Vachette, P.; Durand, D.; Ladant, D.; et al. Stability, structural and functional properties of a monomeric, calcium-loaded adenylate cyclase toxin, CyaA, from Bordetella pertussis. Sci. Rep. 2017. [CrossRef] [PubMed]

15. Barry, E.M.; Weiss, A.A.; Ehrmann, I.E.; Gray, M.C.; Hewlett, E.L.; Goodwin, M.S. Bordetella pertussis adenylate cyclase toxin and haemolytic activities require a second gene, cya C, for activation. J. Bacteriol. 1991, 173, 720-726. [CrossRef] [PubMed]

16. Hackett, M.; Guo, L.; Shabanowitz, J.; Hunt, D.F.; Hewlett, E.L. Internal lysine pamitoylation in adenylate cyclase toxin from Bordetella pertussis. Science 1994, 266, 433-435. [CrossRef] [PubMed]

17. Hackett, M.; Walker, C.B.; Guo, L.; Gray, M.C.; Van Cuyk, S.; Ullmann, A.; Shabanowitz, J.; Hunt, D.F.; Hewlett, E.L.; Sebo, P. Hemolytic, but not cell-invasive activity, of adenylate cyclase toxin is selectively affected by differential fatty-acylation in Escherichia coli. J. Biol. Chem. 1995, 270, 20250-20253. [CrossRef] [PubMed]

18. Bouchez, V.; Douché, T.; Dazas, M.; Delaplane, S.; Matondo, M.; Chamot-Rooke, J.; Guiso, N. Characterisation of Post-translationnal modifications of adenylate-cyclase hemolysin produced by different B. pertussis and B. parapertussis isolates. submitted.

19. Zaretzky, F.R.; Gray, M.C.; Hewlett, E.L. Mechanism of association of adenylate cyclase toxin with the surface of Bordetella pertussis: A role for toxin-filamentous haemagglutinin interaction. Mol. Microbiol. 2002, 45, 1589-1598. [CrossRef] [PubMed] 
20. Hegerle, N.; Guiso, N. Antibody-mediated inhibition of Bordetella pertussis adenylate cyclase-haemolysin-induced macrophage cytotoxicity is influenced by variations in the bacterial population. Microbiology 2014. [CrossRef] [PubMed]

21. Hanawa, T.; Yonezawa, H.; Kawakami, H.; Kamiya, S.; Armstrong, S. Role of Bordetella pertussis RseA in the cell envelope stress response and adenylate cyclase toxin release. Pathog. Dis. 2013, 69, 7-20. [PubMed]

22. Barbier, M.; Bohm, D.; Sen-Killic, E.; Bonnin, C.; Pinheiro, T.; Hoffman, C.; Gray, M.; Hewlett, E.; Damrom, F.H. Modulation of pertussis and adenylate cyclase toxins by sigma factor RpoE in Bordetella pertussis. Infect. Immun. 2017, 85, 1-16. [CrossRef] [PubMed]

23. Guiso, N.; Rocancourt, M.; Szatanik, M.; Alonso, J.M. Bordetella adenylate cyclase is a virulence associated factor and an immune-protective antigen. Microb. Pathog. 1989, 7, 373-380. [CrossRef]

24. Gueirard, P.; Druilhe, P.; Pretolani, M.; Guiso, N. Role of adenylate cyclase-hemolysin in alveolar macrophage apoptosis during Bordetella pertussis infection in vivo. Infect. Immun. 1998, 66, 1718-1725. [PubMed]

25. Dalet, K.; Weber, C.; Guillemot, C.; Njamkepo, E.; Guiso, N. Characterization of adenylate cyclase hemolysin gene duplication in a Bordetella pertussis isolate. Infect. Immun. 2004, 72, 4874-4877. [CrossRef] [PubMed]

26. Bouchez, V.; Hegerle, N.; Strati, N.; Njamkepo, E.; Guiso, N. New data on vaccine antigen deficient Bordetella pertussis isolates. Vaccines 2015. [CrossRef] [PubMed]

27. Chenal, A.C.; Karst, J.C.; Sotomayor-Perez, A.C.; Wozniak, A.C.; Baron, B.; England, P.; Ladant, D. Calcium-induced folding and stabilization of the intrinsically disordered RTX domain of the CyaA toxin. Biophys. J. 2010, 99, 3744-3753. [CrossRef] [PubMed]

28. Guermonprez, P.; Khelef, N.; Bouin, E.; Rieu, P.; Ricciardi-Castagnoli, P.; Guiso, N.; Ladant, D.; Leclerc, C. The adenylate cyclase toxin of Bordetella pertussis binds to target cells via the $\alpha_{M} \beta_{2}$ integrin (CD11b/CD18). J. Exp. Med. 2001, 193, 1035-1039. [CrossRef] [PubMed]

29. El-Azami-El-Idrissi, M.; Bauche, C.; Loucka, J.; Osicka, R.; Sebo, P.; Ladant, D.; Leclerc, C. Interaction of Bordetella pertussis adenylate cyclase with CD11b/CD18: Role of toxin acylation and identification of the main integrin interaction domain. J. Biol. Chem. 2003, 278, 38514-38521. [CrossRef] [PubMed]

30. Vojtova, J.; Kamanova, J.; Sebo, P. Bordetella adenylate cyclase toxin: A swift saboteur of host defense. Curr. Opin. Microbiol. 2006, 9, 69-75. [CrossRef] [PubMed]

31. Karst, J.C.; Barker, R.; Devis, U.; Swann, M.; Davi, M.; Roser, S.J.; Ladant, D.; Chenal, A. Identification of a region that assists membrane insertion and translocation of the catalytic domain of Bordetella pertussis CyaA toxin. J. Biol. Chem. 2012, 287, 9200-9212. [CrossRef] [PubMed]

32. Gray, M.C.; Donato, G.M.; Jones, F.R.; Kim, T.; Hewlett, E.L. Newly secreted adenylate cyclase toxin is responsible for intoxication of target cells by Bordetella pertussis. Mol. Microbiol. 2004, 53, 1709-1719. [CrossRef] [PubMed]

33. Weiss, A.A.; Hewlett, E.L.; Myers, G.A.; Falkow, S. Tn5-induced mutations affecting virulence factors of Bordetella pertussis. Infect. Immun. 1983, 42, 33-41. [PubMed]

34. Khelef, N.; Sakamoto, H.; Guiso, N. Both adenylate cyclase and hemolytic activities are required for Bordetella pertussis to initiate infection. Microb. Pathog. 1992, 12, 227-235. [CrossRef]

35. Skopova, K.; Tomalova, B.; Kanchev, I.; Rossmann, P.; Svedova, M.; Adkins, I.; Bibova, I.; Tomala, J.; Masin, J.; Guiso, N.; et al. Cyclic AMP-Elevating Capacity of Adenylate Cyclase Toxin-Hemolysin Is Sufficient for Lung Infection but Not for Full Virulence of Bordetella pertussis. Infect. Immun. 2017, 85, e00937-16. [CrossRef] [PubMed]

36. Khelef, N.; Zynchlinski, M.; Guiso, N. Bordetella pertussis induces apoptosis in macrophages: Role of adenylate cyclase-hemolysin. Infect. Immun. 1993, 61, 4064-4071. [PubMed]

37. Khelef, N.; Guiso, N. Induction of macrophage apoptosis by Bordetella pertussis adenylate cyclase-hemolysin. FEMS Microbiol. Lett. 1995, 134, 27-32. [CrossRef] [PubMed]

38. Basler, M.; Masin, J.; Osicka, R.; Sebo, P. Pore-forming and enzymatic activities of Bordetella pertussis adenylate cyclase toxin synergize in promoting lysis of monocytes. Infect. Immun. 2006, 74, 2207-2214. [CrossRef] [PubMed]

39. Fiser, R.; Masin, J.; Basler, M.; Krǔšek, J.; Špuláková, V.; Konopàsek, I.; Sebo, P. Third activity of Bordetella adenylate cyclase (AC) toxin-hemolysin Membrane translocation of AC domain polypeptide promotes calcium influx into CD11b+ monocytes independently of the catalytic and hemolytic activities. J. Biol. Chem. 2007, 282, 2808-2820. [CrossRef] [PubMed] 
40. Mobberley-Schuman, P.S.; Weiss, A.A. Influence of CR3 (CD11b/CD18) expression on phagocytosis of Bordetella pertussis by human neutrophils. Infect. Immun. 2005, 73, 7317-7323. [CrossRef] [PubMed]

41. Andreasen, C.; Carbonetti, N.H. Role of neutrophils in response to Bordetella pertussis infection in mice. Infect. Immun. 2009, 77, 1182-1188. [CrossRef] [PubMed]

42. Bassinet, L.; Gueirard, P.; Maître, B.; Housset, B.; Guiso, N. Invasion of human tracheal epithelial cells by Bordetella pertussis. The role of adhesins and toxins in this process. Infect. Immun. 2000, 68, 1934-1941. [CrossRef] [PubMed]

43. Bassinet, L.; Fitting, C.; Housset, B.; Cavaillon, J.M.; Guiso, N. Bordetella pertussis adenylate cyclase-hemolysin induces interleukin-6 secretion by human tracheal epithelial cells. Infect. Immun. 2004, 72, 5530-5533. [CrossRef] [PubMed]

44. Khelef, N.; Bachelet, C.M.; Vargaftig, B.; Guiso, N. Characterization of murine lung inflammation after infection with parental Bordetella pertussis and mutants deficient in adhesins or toxins. Infect. Immun. 1994, 62, 2893-2900. [PubMed]

45. Martín, C.; Etxaniz, A.; Uribe, K.B.; Etxebarria, A.; González-Bullón, D.; Arlucea, J.; Goñi, F.M.; Aréchaga, J.; Ostolaza, H. Adenylate Cyclase Toxin promotes bacterial internalisation into non phagocytic cells. Sci. Rep. 2015. [CrossRef] [PubMed]

46. Boschwitz, J.S.; Batanghari, J.W.; Kedem, H.; Relman, D.A. Bordetella pertussis infection of human monocytes inhibits antigen-dependent CD4 T cell proliferation. J. Infect. Dis. 1997, 176, 678-686. [CrossRef] [PubMed]

47. Njamkepo, E.; Pinot, F.; Francois, D.; Guiso, N.; Polla, B.S.; Bachelet, M. Adaptive responses of human monocytes infected by Bordetella pertussis: The role of adenylate cyclase hemolysin. J. Cell. Physiol. 2000, 183, 91-99. [CrossRef]

48. Fedele, G.; Spensieri, F.; Palazzo, R.; Nasso, M.; Cheung, G.Y.; Coote, J.G.; Ausiello, C.M. Bordetella pertussis Commits Human Dendritic Cells to Promote a Th1/Th17, Response through the Activity of Adenylate Cyclase Toxin and MAPK-Pathways. PLoS ONE 2010. [CrossRef] [PubMed]

49. Adkins, I.; Kamanova, J.; Kocourkova, A.; Svedova, M.; Tomala, J.; Janova, H.; Masin, J.; Chladkova, B.; Bumba, L.; Kovar, M.; et al. Bordetella adenylate cyclase toxin differentially modulates Toll-like receptorstimulated activation, migration and $\mathrm{T}$ cell stimulatory capacity of dendritic cells. PLoS ONE 2014. [CrossRef] [PubMed]

50. Eby, J.C.; Gray, M.C.; Warfel, J.M.; Paddock, C.D.; Jones, T.F.; Day, S.R.; Bowden, J.; Poulter, M.D.; Donato, G.M.; Merkel, T.J.; et al. Quantification of the adenylate cyclase toxin of Bordetella pertussis in vitro and during respiratory infection. Infect. Immun. 2013, 81, 1390-1398. [CrossRef] [PubMed]

51. Farfel, Z.; Konen, S.; Wiertz, E.; Klapmuts, R.; Addys, P.A.K.; Hanski, E. Antibodies to Borderella pertussis adenylate cyclase are produced in man during pertussis infection and after vaccination. J. Med. Microbiol. 1990, 32, 173-177. [CrossRef] [PubMed]

52. Betsou, F.; Sebo, P.; Guiso, N. The C-terminal domain is essential for protective activity of the Bordetella pertussis adenylate cyclase-hemolysin. Infect. Immun. 1995, 63, 3309-3315. [PubMed]

53. Cherry, J.D.; Xing, D.; Newland, P.; Patel, K.; Heininger, U.; Corbel, M.J. Determination of Serum Antibody to Bordetella pertussis Adenylate Cyclase Toxin in Vaccinated and Unvaccinated Children and in Children and Adults with Pertussis. Clin. Infect. Dis. 2004, 38, 502-507. [CrossRef] [PubMed]

54. Eby, J.C.; Gray, M.C.; Warfel, J.M.; Merkel, T.J.; Hewlett, E.L. Use of a toxin neutralization assay to characterize the serologic response to adenylate cyclase toxin after Infection with Bordetella pertussis. Clin. Vaccine Immunol. 2017, 24, e00370-16. [CrossRef] [PubMed]

55. Guiso, N.; Berbers, G.; Fry, N.K.; He, Q.; Riffelmann, M.; Wirsing von König, C.H.; EU Pertstrain group. What to do and what not to do in serological diagnosis of pertussis: Recommendations from EU reference laboratories. Eur. J. Clin. Microbiol. Infect. Dis. 2011, 30, 307-311. [CrossRef] [PubMed]

56. Guiso, N.; Szaranik, M.; Rocancourt, M. Protective activity of Bordetella adenylate cyclase against bacterial colonization. Microb. Pathog. 1991, 11, 423-431. [CrossRef]

57. Betsou, F.; Sebo, P.; Guiso, N. CyaC-mediated activation is important not only for toxic but also for protective activities of Bordetella pertussis adenylate cyclase-hemolysin. Infect. Immun. 1993, 61, 3583-3589. [PubMed]

58. Wang, X.; Maynard, J.A. The Bordetella Adenylate Cyclase Repeat-in-Toxin (RTX) Domain Is Immunodominant and Elicits Neutralizing Antibodies. J. Biol. Chem. 2015, 290, 3576-3591. [CrossRef] [PubMed] 
59. Wang, X.; Stapleton, J.A.; Klesmith, J.R.; Hewlett, E.L.; Whitehead, T.A.; Maynard, J. Fine Epitope Mapping of Two Antibodies Neutralizing the Bordetella Adenylate Cyclase Toxin. Biochimie 2017, 56, 1324-1336. [CrossRef] [PubMed]

60. Chenal-Francisque, V.; Caro, V.; Boursaux-Eude, C.; Guiso, N. Genomic analysis of the adenylate cyclase-hemolysin C-terminal region of Bordetella pertussis, Bordetella parapertussis and Bordetella bronchiseptica. Res. Microbiol. 2009, 160, 330-336. [CrossRef] [PubMed]

61. Brézin, C.; Guiso, N.; Ladant, D.; Djavadi-Ohaniance, L.; Megret, F.; Onyeocha, I.; Alonso, J.-M. Protective effects of anti-Bordetella pertussis adenylate cyclase antibodies against lethal respiratory infection of the mouse. FEMS Microbiol. Lett. 1987, 42, 75-80. [CrossRef]

62. Faiz-Kazi, Y.; Hussain, Q. Monospecific antibody against Bordetella pertussis Adenylate Cyclase protects from Pertussis. J. Microbiol. Infect. Dis. 2012, 2, 36-43.

63. Ross, P.J.; Lavelle, E.C.; Mills, K.H.; Boyd, A.P. Adenylate cyclase toxin from Bordetella pertussis synergizes with lipopolysaccharide to promote innate interleukin-10 production and enhances the induction of Th2 and regulatory T cells. Infect. Immun. 2004, 72, 1568-1579. [CrossRef] [PubMed]

64. Cheung, G.Y.C.; Xing, D.; Prior, S.; Corbel, M.; Parton, R.; Coote, J.G. Effect of Different Forms of Adenylate Cyclase Toxin of Bordetella pertussis on Protection Afforded by an acellular Pertussis Vaccine in a Murine Model. Infect. Immun. 2006, 74, 6797-6805. [CrossRef] [PubMed]

65. Gerlach, G.; von Wintzingerode, F.; Middendorf, B.; Gross, R. Evolutionary trends in the genus Bordetella. Microbes Infect. 2001, 3, 61-72. [CrossRef]

66. Leblay, K.; Gueirard, P.; Guiso, N.; Chaby, R. Antigenic polymorphism of the lipopolysaccharides from human and animal isolates of Bordetella bronchiseptica. Microbiology 1997, 143, 1433-1441.

67. Betsou, F.; Seismiro, O.; Danchin, A.; Guiso, N. Cloning and sequence of the Bordetella bronchiseptica adenylate cyclase-hemolysin-encoding gene: Comparison with the Bordetella pertussis gene. Gene 1995, 162, 165-166. [CrossRef]

68. Gueirard, P.; Guiso, N. Virulence of Bordetella bronchiseptica: Role of adenylate cyclase-hemolysin. Infect. Immun. 1993, 61, 4072-4078. [PubMed]

69. El Hamidi, A.; Novikov, A.; Karibian, D.; Perry, M.B.; Caroff, M. Structural characterization of Bordetella parapertussis lipid A. J. Lipid Res. 2009, 50, 854-859. [CrossRef] [PubMed]

70. Bauer, M.E.; Welch, R.A. Pleiotropic Effects of a Mutation in $r f a C$ on Escherichia coli Hemolysin. Infect. Immun. 1997, 65, 2218-2224. [PubMed]

71. Ramjeet, M.; Cox, A.D.; Hancock, M.A.; Mourez, M.; Labrie, J.; Gottschalk, M.; Jacques, M. Mutation in the LPS outer core biosynthesis gene, galU, affects LPS interaction with the RTX toxins ApxI and ApxII and cytolytic activity of Actinobacillus pleuropneumoniae serotype 1. Mol. Microbiol. 2008, 70, 221-235. [CrossRef] [PubMed]

72. Gueirard, P.; Weber, C.; Le Coustumier, A.; Guiso, N. Human Bordetella bronchiseptica infection related to contact with infected animals: Persistence of the bacteria in the host. J. Clin. Microbiol. 1995, 33, 2002-2006. [PubMed]

73. Buboltz, A.M.; Nicholson, T.M.; Parette, M.R.; Hester, S.E.; Parkhill, J.; Harvill, E.T. Replacement of adenylate cyclase toxin in a lineage of Bordetella bronchiseptica. J. Bacteriol. 2008, 190, 5502-5511. [CrossRef] [PubMed]

74. El Khatib, N.; Ferroni, A.; Le Bourgeois, M.; Chedevergne, D.; Clairicia, M.; Avril, H.; Guiso, N.; Sermet-Gaudelus, I. Persistent Bordetella bronchiseptica infection in a child with cystic fibrosis: Relationship to bacterial phenotype. J. Cyst. Fibros. 2015, 14, E13-E15. [CrossRef] [PubMed]

75. Gueirard, P.; Minoprio, P.; Guiso, N. Intranasal Inoculation of Bordetella Bronchiseptica in Mice Induces Long-Lasting Antibody and T-Cell MediatedImmune Responses Scand. J. Immunol. 1996, 43, 181-192.

76. Hibrand-Saint OYant, L.; Bourges, D.; Chevaleyre, C.; Raze, D.; Locht, L.; Salmon, H. Role of Bordetella bronchiseptica adenylate cyclase in intranasal infection and in development of local and systemic immune responses in piglet. Vet. Res. 2005, 36, 63-70. [CrossRef] [PubMed]

77. Hoffman, C.; Eby, J.; Gray, M.; Damron, F.H.; Melvin, J.; Cotter, P.; Hewlett, E. Bordetella adenylate cyclase toxin interacts with filamentous haemagglutinin to inhibit biofilm formation in vitro. Mol. Microbiol. 2016. [CrossRef]

78. Irie, Y.; Mattoo, S.; Yuk, M.H. The Bvg virulence control system regulates biofilm formation in Bordetella bronchiseptica. J. Bacteriol. 2004, 186, 5692-5698. [CrossRef] [PubMed] 
79. Khelef, N.; Danve, B.; Quentin-Millet, M.J.; Guiso, N. Bordetella pertussis and Bordetella parapertussis: Two immunological distinct species. Infect. Immun. 1993, 61, 486-490. [PubMed]

80. Basheer, S.M.; Guiso, N.; Tirsoaga, A.; Caroff, M.; Novikov, A. Structural modifications occurring in lipid A of Bordetella bronchiseptica clinical isolates as demonstrated by matrix-asisted laser desorption/ionization time-of-flight mass spectrometry. Rapid Commun. Mass Spectrom. 2011, 25, 1075-1081.

81. Albitar-Nehme, S.; Basheer, S.M.; Njamkepo, E.; Brisson, J.R.; Guiso, N.; Caroff, M. Comparison of lipopolysaccharide structures of Bordetella pertussis clinical isolates from pre- and post-vaccine era. Carbohydr. Res. 2013, 378, 56-62. [CrossRef] [PubMed]

82. Osickova, A.; Masin, J.; Fayolle, C.; Krusek, J.; Basler, M.; Pospisilova, E.; Leclerc, C.; Osicka, R.; Sebo, P. Adenylate cyclase toxin translocates across target cell membrane without forming a pore. Mol. Microbiol. 2010, 75, 1550-1562. [CrossRef] [PubMed]

83. Sebo, P.; Osicka, R.; Masin, J. Adenylate cyclase toxin-hemolysin relevance for pertussis vaccines. Expert Rev. Vaccines 2014, 13, 1215-1227.

84. Hozbor, D. Outer membrane vesicles: An attractive candidate for pertussis vaccines. Expert Rev. Vaccines 2017, 16, 193-196. [CrossRef] [PubMed]

85. Raeven, R.H.M.; Brummelman, J.; Pennings, J.L.A.; van der Maas, L.; Tilstra, W.; Helm, K.; van Riet, E.; Jiskoot, W.; van Els, C.A.C.M.; Han, W.G.H.; et al. Bordetella pertussis outer membrane vesicle vaccine confers equal efficacy in mice with milder inflammatory responses compared to a whole-cell vaccine. Sci. Rep. 2016. [CrossRef] [PubMed]

86. Tubiana, S.; Belchior, E.; Guillot, S.; Guiso, N.; Levy-bruhl, D. Monitoring the impact of vaccination on infant pertussis using an active hospital-based pediatric surveillance network: Results from seventeen years' experience, 1996-2012, France. Pediatr. Infect. Dis. J. 2015, 34, 814-820. [CrossRef] [PubMed]

87. Linz, B.; Ivanov, Y.V.; Preston, A.; Brinkac, L.; Parkhill, J.; Kim, M.; Harris, S.R.; Goodfield, L.L.; Fry, N.K.; Gorringe, A.R.; et al. Acquisition and loss of virulence-associated factors during genome evolution and speciation in three clades of Bordetella species. BMC Genom. 2016, 17, 767-784. [CrossRef] [PubMed]

88. Bokhari, H.; Said, F.; Syed, M.A.; Mughal, A.; Kazi, Y.F.; Heuvelman, K.; Mooi, F. Whooping cough in Pakistan: Bordetella pertussis vs Bordetella parapertussis in 2005-2009. Scand. J. Infect. Dis. 2011, 43, 818-820. [CrossRef] [PubMed]

(c) 2017 by the author. Licensee MDPI, Basel, Switzerland. This article is an open access article distributed under the terms and conditions of the Creative Commons Attribution (CC BY) license (http://creativecommons.org/licenses/by/4.0/). 